\title{
Minimaal invasieve behandeling van epilepsie
}

Epilepsiechirurgie is een evidence-based, curatieve therapie voor een geselecteerde groep van patiënten met chronische, medicatie-resistente, focale epilepsie (Engel et al., 2012). Er bestaan meerdere pre- en postoperatieve predictoren voor een goede postoperatieve aanvals-uitkomst zoals een aantoonbare laesie op beeldvormend onderzoek (3Tesla MRI), strikt regionale/focale epileptiforme ontladingen in het EEG, en een focus op afstand van eloquente cortex (prechirurgische predictoren) evenals een complete lesionectomie, aard van de verwijderde laesie (Lamberink et al., 2020) en complete verwijdering van de seizure onset zone (SOZ) (postchirurgische predictoren) (Barba et al., 2020). Afhankelijk van de individuele indicatiestelling kan op lange termijn een percentage van 50-60\%, en in bepaalde cases zelfs nog hoger, aanvalsvrijheid na operatie bereikt worden (Liu et al., 20I5). De laatste jaren zijn er naast resectieve en disconnectieve epilepsiechirurgie bepaalde vormen van minimaal invasieve (chirurgische) behandeling bijgekomen die de voorkeur boven resectieve chirurgie kunnen hebben in een bepaalde subgroep van patiënten. De vier belangrijkste minimaal invasieve, in opzet curatieve, therapiën op dit moment zijn: I. Stereo-EEG Radiofrequente ThermoCoagulatie (SEEG RFTC), 2. MRIguided Laser Interstitial ThermoTherapy (MRI-g LITT), 3. MRIguided High Intensity Focused Ultrasound (MRI-g FUS), en 4. Stereotactische Radiochirurgie. In de categorie palliatieve therapiën zijn er eveneens een drietal minimaal invasieve behandelingsopties, namelijk Nervus Vagus stimulatie (NVS), Diepe Hersenstimulatie (DBS) en Responsieve Neurostimulatie (RNS). In deze rubriek worden de eerste twee minimaal invasieve, in opzet curatieve behandelingen (SEEG RFTC en MRI-g-LITT) besproken evenals de RNS therapie.

\section{Stereo-EEG Radiofrequente ThermoCoagulatie} De stereotactische techniek om multipele diepte-elektroden te implanteren (SEEG) als invasieve diagnostische methode in de workup voor resectieve epilepsiechirurgie werd ontwikkeld en als eerste toegepast door de Franse neuroloog/psychiater-en-later neurochirurg Jean Talairach en neuroloog/neurofysioloog Jean Bancaud, beiden destijds werkzaam in het Hôpital Sainte Anne te Parijs. In I957, acht jaar voor de landmark paper (Bancaud en Tailarach, I965) vond de eerste implantatie in Parijs plaats (Cardinale et al., 20I6). Gedurende decennia werd de SEEG-techniek uitsluitend in Frankrijk en Noord-Italië toegepast. De afgelopen jaren is deze techniek in de meeste internationale epilepsiechirurgie centra ingevoerd naast de traditionele subdurale grid- en strip-elektroden. In 2004 beschreef neurochirurg Marc Guenot en zijn team voor het eerst dat het SEEG niet alleen voor diagnostische doeleinden gebruikt kan worden, maar door middel van radiofrequente thermocoagulatie, ook als minimaal invasieve behandeling ingezet kan worden (Guénot et al., 2004). Recent verscheen een meta-analyse over deze ablatieve techniek met daarin duidelijke aanbevelingen (Bourdillon et al., 20I8). In een bijdrage van Colon en collega's worden de resultaten gerapporteerd van een cohort patiënten die in het Academisch Centrum voor Epileptologie (ACE), MUMC+l Kempenhaeghe tussen 2016 en 2020 de SEEG RFTC behandeling ondergingen.

\section{MRI-guided Laser Interstitial ThermoTherapy} MRI-guided Laser Interstitial ThermoTherapy (MRI-g LITT) maakt gebruik van locale verhitting door laser-technologie via een stereotactisch ingebrachte catheter. Met behulp van MRI-thermometrie kan real-time de temperatuur gecontroleerd worden tijdens het aanbrengen van intraparenchymateuze cerebrale laesies. De eerste humane toepassing van de MRI-g-LITT vond in 2008 plaats in de Verenigde Staten bij zes patiënten met hersenmetastasen (Carpentier et al., 2008). Enkele jaren daarna werd dezelfde techniek toegepast in vijf pediatrische patiënten met epilepsie en diverse cerebrale pathologische laesies (Curry et al., 20I2). Sinds maart 2018 is de technologie voor MRI-g LITT goedgekeurd in Europa en werden er meerdere epilepsiepatiënten behandeld. Binnen Nederland zal er in de tweede helft van 202I een pilot studie met de MRI-g-LITT voor een beperkt aantal patiënten gedaan worden in het Universitair Medisch Centrum Utrecht. 
Een goed voorbeeld van een categorie patiënten die voor MRI-g-LITT in aanmerking kan komen zijn patiënten met een hypothalamus hamartoom. Patiënten presenteren zich meestal met een vorm van gelastische epilepsie. Dit is een zeldzame congenitale aandoening ( $<$ I:I0o.00o kinderen) die onderverdeeld wordt qua lokalisatie in twee hoofdcategorieën. De eerste groep bestaat uit de intrahypothalame laesies die een relatie hebben met de derde ventrikel en de corpora mammilaria en de typische gelastische aanvallen veroorzaken. De tweede groep zijn de parahypothalame laesies die een relatie hebben met de anterieure hypothalamus, het tuber cinereum en de bodem van de derde ventrikel en aanleiding kunnen geven tot symptomen van pubertas praecox en multipele aanvalstypen, cognitieve achteruitgang en psychiatrische problematiek (Carballo et al., 2020). In een bijdrage van Wagner en collega's wordt het resultaat van deze therapie beschreven voor een cohort patiënten die vanuit ACE verwezen werden naar collega Dr Daniel J. Curry in het Texas Children's hospital in Houston, Verenigde Staten.

\section{Responsieve NeuroStimulatie}

Responsieve Neurostimulatie (RNS) werd door de FDA in 20I3 goedgekeurd (Brandy, 20I8) en inmiddels zijn wereldwijd rond de 2000 patiënten hiermee behandeld. Onder andere patiënten met een chronische, focale epilepsie en het focus in eloquente cortex, die niet zijn geïndiceerd voor resectie, zijn kandidaten voor closed-loop neurostimulatie. In de meeste publicaties wordt een reductie van de aanvalsfrequentie gerapporteerd waardoor RNS in de categorie palliatieve behandelingen valt. Sinds publicaties over veiligheid en efficacy van deze therapie (Morrell, 20II) is de toepassing mondiaal toegenomen. Het unieke voordeel, in tegenstelling tot de beide andere vormen van minimaal invasieve neurostimulatie, is dat er chronisch elektrocorticografisch wordt gemeten, hetgeen een bron van neurofysiologische data oplevert. Daartegenover staat dat deze behandeling minder minimaal invasief is dan NVS en DBS. De efficacy van de RNS-therapie ten opzichte van NVS en DBS is echter nog niet duidelijk vastgesteld (Brandy en Rao, 20I8). In een bijdrage aan deze rubriek wordt door Dorien van Blooijs gedetailleerd over de eerste Nederlandse ervaringen met deze techniek gerapporteerd.

\section{Referenties}

Bancaud J, Talairach J.(I965) La Stéreo-ÉlectroEncéphaloGraphie dans l'Épilepsie. Bancaud J, Talairach J (Eds.), Masson \& Cie, Editeurs, Paris

Barba C, Cossu M, et al. (2020) Temporal lobe epilepsy surgery in children and adults: A multicenter study. Epilepsia Dec I. doi: Io.IIII/epi.r6772. Epub ahead of print. PMID: 33258120.

Bourdillon P, Cucherat M, et al. (2018) Stereo-electroence- phalography-guided radiofrequency thermocoagulation in patients with focal epilepsy: a systematic review and meta-analysis. Epilepsia 59(12):2296-2304

Brandy M, Rao V. (20I8) Responsive neurostimulation: Candidates and considerations. Epilepsy Behav 88; 388-395

Cardinale F, Gonzalez-Martinez J, et al. (2016) SEEG, Happy anniversary. World Neurosurgery 85:1-2

Guénot M, Isnard J, et al. (2004) SEEG-guided RF Thermocoagulation of epileptic foci: feasibility, safety and preliminary results. Epilepsia 45(11):1368-1374

Carballo Cuello CM, De Jesus O. (2020) Hypothalamic hamartoma. In: StatPearls [Internet]. Treasure Island (FL): StatPearls Publishing; 2020 Jan-. PMID: 32809498

Carpentier A, Itzcovitz J, et al. (2008) Real-time magnetic resonance-guided-laser thermal therapy for focal metastatic brain tumours. Neurosurgery 63; ONS 21

Curry DJ, Gowda A, et al. (20I2) MR-guided stereotactic laser ablation of epileptogenic foci in children.

Epilepsy Behav 24; 408-414

Morrell MJ. (20II) RNS system in Epilepsy Study Group. Responsive cortical stimulation for the treatment of medically intractable partial epilepsy.

Neurology 77; 1295-1304

Lamberink HJ, Otte WM, et al. (2020) Seizure outcome and use of antiepileptic drugs after epilepsy surgery according to histopathological diagnosis: a retrospective multicenter cohort study. Lancet Neurol. 2020; 19(9): 748-757

Liu XL, Yang XL, et al. (20I5) Clinical outcomes and quality of life following surgical treatment of refractory epilepsy: a systematic review and meta-analysis. Medicine (Baltimore); 94: 2500 